\title{
PASSADO, PRESENTE E FUTURO DO ENSINO DE LÍNGUAS NO BRASIL: MÉTODOS E POLÍTICAS
}

Marina Grilli ${ }^{1}$

\begin{abstract}
Resumo
Este trabalho revisita a história do ensino de línguas no Brasil sob um olhar questionador. O objetivo é fornecer subsídios para um posicionamento histórico-crítico dos professores de línguas no Brasil. A introdução contribui para situar a época em que essas reflexões estão sendo realizadas, entre novos movimentos de globalização facilitados pelas novas tecnologias, de um lado, e o desmonte da educação pública brasileira, de outro lado. A seguir, delineia-se um panorama histórico-político do ensino de línguas no país, situando três aspectos em paralelo: as línguas ensinadas nas escolas desde o início da colonização, as políticas linguísticas concernentes a esse ensino e os métodos de ensino de línguas vigentes em cada época. Então, observa-se algumas relações entre esses aspectos e as condições atuais de ensino de línguas nas escolas brasileiras. Na conclusão, defende-se uma mudança de perspectiva acerca do ensino de línguas hegemônicas na escola.
\end{abstract}

Palavras-chave: Ensino de línguas. Política linguística. Neoliberalismo.

\section{PAST, PRESENT AND FUTURE OF LANGUAGE TEACHING IN BRAZIL: METHODS AND POLICIES}

\begin{abstract}
This paper revisits the history of language teaching in Brazil from a questioning outlook, aiming to provide support for a historical-critical positioning of language teachers in Brazil. The introduction contributes to situating the time when these reflections are being carried out, between new globalization movements facilitated by new technologies, on the one hand, and the dismantling of Brazilian public education, on the other hand. The following section presents a three-tier historical-political overview of language teaching in the country, considering the languages taught in schools since the beginning of the colonization, the language policies concerning this teaching and the popular methods of language teaching at each time. Then, we establish some relations between these aspects and the current conditions of language teaching in Brazilian schools. In the conclusion, we advocate for a change of perspective regarding the teaching of hegemonic languages at school.
\end{abstract}

Keywords: Language teaching. Language policy. Neoliberalism.

\section{INTRODUÇÃO}

Passadas quase duas décadas do século XXI da era cristã, o Brasil vive tempos sombrios. A combinação do sucateamento do ensino público, do aumento das dificuldades de ascensão a

\footnotetext{
${ }^{1}$ Universidade de São Paulo (USP), São Paulo - São Paulo - Brasil. Doutoranda em Educação pela Universidade de São Paulo (USP). ORCID < http://orcid.org/0000-0002-6324-7030>. E-mail: marina.grilli.s@gmail.com.
} 


\section{Linguagens - Revista de Letras, Artes e Comunicação - ISSN 1981- 9943 \\ Blumenau, v. 12, n. 3, p. 415-435, set./dez. 2018. \\ DOI: http://dx.doi.org/10.7867/1981-9943.2018v12n3p415-435}

estratos sociais mais altos e da proliferação de fontes de informação não confiáveis por meio de recursos da internet resultou desastrosa. Além de o conhecimento de nossa História ser menosprezado por jovens há tempos, como efeito do desprestígio das Ciências Humanas em um país que vive processos de neoliberalização há pelo menos duas décadas, há quem hoje afirme convictamente que determinados eventos históricos jamais chegaram a ocorrer, distorcendo, assim, seus significados dentro das populações diretamente afetadas e seus efeitos sobre as populações indiretamente afetadas por esses eventos.

Antes fossem tais "opiniões" exclusividade de quem não teve oportunidade de estudar - caso que nem sequer deveria existir -, causando compaixão nas demais parcelas da população. Contudo, é com assombro que assistimos ao crescimento de tais figuras ao ponto de se disfarçarem de autoridades, almejando alguns dos principais postos de comando do país. O que serve de "consolo" - note-se a ironia - é observar ocorrências semelhantes em outros países, com o movimento antivacinação fazendo ressurgirem doenças erradicadas há décadas, e grandes multinacionais exploradoras de petróleo patrocinando congressos milionários cuja agenda é contestar o incontestável aquecimento global.

Diante desse cenário, a profisssão docente, que também há décadas tem sido desqualificada e destituída de agência, perde ainda mais de seu já parco "prestígio", na falta de um termo mais adequado. O mesmo se pode afirmar do trabalho de pesquisa: quanto vale a Ciência, em tempos de congelamento dos "gastos" com educação e saúde? Quanto vale, aliás, a própria Educação, se o trabalho do patrono da educação brasileira, tema de estudo em diversos institutos ao redor do globo e terceiro teórico mais citado em trabalhos acadêmicos no mundo, tem sido sistematicamente desacreditado?

Aprofundemos esses questionamentos tendo em mente o trabalho do professor de línguas. Este, não só destituído de agência enquanto professor, vê ainda seu trabalho ser submetido aos mais diversos critérios definidos por organizações internacionais. E sabe que tais organizações, além de não terem contato algum com a realidade em que os profissionais de países não-hegemônicos desenvolvem seu trabalho, também desconsideram a pluralidade de registros que podem surgir no âmbito de uma mesma língua. Já não é suficiente pensar em variações diatópicas dentro de um mesmo país em que a língua em questão é majoritária, ou variações diastráticas já consolidadas na oralidade das camadas populares em regiões inteiras. É preciso reconhecer, no âmbito do ensino de línguas, o uso que qualquer usuário de qualquer língua lhe confere, em qualquer gênero discursivo, dispondo de qualquer nível de conhecimento da língua em questão. 


\section{Linguagens - Revista de Letras, Artes e Comunicação - ISSN 1981- 9943 \\ Blumenau, v. 12, n. 3, p. 415-435, set./dez. 2018.}

DOI: http://dx.doi.org/10.7867/1981-9943.2018v12n3p415-435

Enquanto isso, o grande volume de pesquisas recentes na área de formação de professores de línguas busca legitimar a profissão docente. Sem ignorar as contribuições desses trabalhos para a compreensão do quão complexa é a tarefa de ensinar línguas, os desafios da sociedade de hoje, brevemente comentados acima, exigem ainda mais estudos e reflexões que considerem as diversas manifestações linguísticas.

Pensando nessas questões, a originalidade deste artigo reside na retrospectiva histórica do ensino de línguas no Brasil baseada em três aspectos paralelos: as línguas ensinadas; os métodos de ensino de línguas vigentes em cada época; as questões políticas que permeavam o ensino de línguas e a educação escolar como um todo. Na primeira parte, apresenta-se essa retrospectiva; na segunda parte, esses dados são interpretados de forma crítica, e a conclusão delineia uma sugestão de mudança de ponto de vista no ensino de línguas brasileiro.

Nosso objetivo aqui é mais do que elencar os motivos que levaram a população brasileira a um conhecimento tão deficiente de línguas, oferecendo subsídios para um posicionamento histórico-crítico dos professores de línguas no Brasil; é também apontar por que precisamos de um novo paradigma para o ensino de línguas no Brasil, mais adequado aos tempos em que vivemos.

\section{HISTÓRICO DO ENSINO DE LÍNGUAS NO BRASIL: PROCEDIMENTOS E ASPECTOS POLÍTICOS}

Segundo Auroux (1992), o advento da escrita foi o marco da primeira revolução técnicolinguística, isto é, da primeira revolução da linguagem que teve "consequências práticas para a organização das sociedades humanas" (AUROUX, 1992, p. 35). A segunda revolução técnicolinguística teria sido o advento da gramatização massiva: ao mesmo tempo em que a gramática servia para descrever a língua latina, bem como os vernáculos dela decorrentes, servia também como método de aprendizagem. Com foco na Europa e na tradição linguística greco-latina, embora concomitante à de outros continentes, a gramatização ocorreu em paralelo ao giro nas ciências da natureza, da concepção aristotélica para a físico-matemática (AUROUX, 1992, p. 35-37).

Embora os primeiros movimentos de gramatização datem do século VI, não se comparam aos processos da segunda revolução técnico-linguística, a partir da qual o francês, o italiano, o espanhol e o português se expandiram a ponto de protagonizar a história da Europa, juntamente com o inglês e o alemão. 


\section{Linguagens - Revista de Letras, Artes e Comunicação - ISSN 1981- 9943 \\ Blumenau, v. 12, n. 3, p. 415-435, set./dez. 2018. \\ DOI: http://dx.doi.org/10.7867/1981-9943.2018v12n3p415-435}

Os movimentos de colonização tiveram grande influência no papel de protagonismo dessas línguas. Nas páginas a seguir, retomamos pontos importantes da história da educação no Brasil, desde a invasão do país pelos colonizadores portugueses, popularmente denominada “descobrimento" - ou, nas palavras de Espírito Santo e Santos (2018, p. 155), “invenção" - até a contemporaneidade, a partir da obra de Saviani (2007). Desse modo, estabelecemos uma base histórica para a reflexão sobre as constantes transformações da educação linguística na sociedade.

\subsection{EUROPA: DO SURGIMENTO DAS LÍNGUAS NEOLATINAS ÀS GRANDES NAVEGAÇÕES}

Séculos antes da chegada dos portugueses ao Brasil, a fragmentação do Império Romano levou à fragmentação do latim nas línguas neolatinas, ao mesmo tempo em que a língua de administração e da cultura intelectual e religiosa permanecia sendo o latim - inclusive em locais onde se desenvolviam línguas indo-europeias não-latinas (AUROUX, 1992, p. 41). Dessa forma, as outras línguas serviam como base para o aprendizado do latim, e, sendo este geralmente aprendido como segunda língua, estabeleceu a base da gramática como técnica de aprendizagem (AUROUX, 1992, p. 42). Falaremos mais sobre o desenvolvimento do método de ensino do latim e de outras línguas na seção a seguir.

A fragmentação do Império Romano do Ocidente entre os séculos VII e IX provocou o surgimento das línguas neolatinas, enfraquecendo o papel do latim enquanto vernáculo. Este permanecia, entretanto, como língua de veiculação da cultura intelectual e religiosa. A partir do século IX, a restauração voluntária da cultura latina na Europa alçaria o latim ao status de segunda língua, transformando a gramática latina em técnica de aprendizagem de língua: “a gramática latina se torna simultaneamente uma técnica pedagógica de aprendizagem das línguas e um meio de descrevê-las" (AUROUX, 1992, p. 36).

Paulani (2012, p. 89-90) resume a era das navegações como uma fase de acumulação primitiva, sendo os países descobertos considerados como "puro e simples objeto de espoliação". No âmbito das línguas e culturas, Espírito Santo e Santos (2018, p. 154) observam que o projeto era transformá-las “em objetos de conhecimento europeu, isto é, inventar línguas e culturas não semelhantes às europeias, mas sim semelhantes ao que os europeus achavam como elas deveriam ser". 


\section{Linguagens - Revista de Letras, Artes e Comunicação - ISSN 1981- 9943 \\ Blumenau, v. 12, n. 3, p. 415-435, set./dez. 2018. \\ DOI: http://dx.doi.org/10.7867/1981-9943.2018v12n3p415-435}

De acordo com Saviani (2007, p. 25), a chegada dos portugueses trouxe o Brasil para dentro dos muros da civilização ocidental cristã. As implicações dessa mudança serão discutidas na seção a seguir.

\subsection{SÉCULOS XVI A XVIII: O ESTUDO DOS CLÁSSICOS E A IMPOSIÇÃO DO PORTUGUÊS}

Imposição dos colonizadores portugueses, a educação jesuítica não deve ser compreendida simplesmente como força aliada à colonização, e sim, como força integrada ao processo de colonização (PAIVA, 1982, p. 97 apud SAVIANI, 2007, p. 31).

O ensino católico imposto aos nativos brasileiros e, pouco mais tarde, aos africanos trazidos à força ao país para a realização de trabalho escravo, iniciou de forma violenta um longo processo de aculturação dessas populações; se tanto esses povos escravizados quanto os europeus dispunham de seus recursos de linguagem de forma integrada a suas práticas religiosas e culturais de modo geral, a imposição da língua portuguesa e da ideologia cristã sobre eles teve efeitos devastadores.

O longo histórico de exploração econômica dos nativos brasileiros e dos africanos por parte dos jesuítas era constantemente denunciado pelos empreendedores seculares. O motivo: estes concorriam em desvantagem contra os jesuítas por não desfrutarem das mesmas facilidades fiscais que aqueles. Assim, o conflito entre a Companhia de Jesus e as Coroas de Portugal e Espanha, unificadas a partir 1729, foi se intensificando, o que culminou na expulsão dos jesuítas "do território português e de todas as terras de além-mar" em 1759 (SAVIANI, 2007, p. 67-82). Meses antes, o Alvará de 28 de junho daquele ano já havia determinado o fechamento dos colégios e da Universidade de Évora, fundados pelos jesuítas.

Quanto ao progresso das letras, o "Diretório dos Índios", de autoria do mesmo Marquês de Pombal, instaurava a oficialização da língua portuguesa no Brasil em 1758 (ESPÍRITO SANTO e SANTOS, 2018, p. 155).

Enquanto isso, em Portugal, florescia o Iluminismo, em contraposição à atmosfera religiosa ainda dominante. Em 1775, o Marquês de Pombal apresentou os nove princípios básicos do novo Estado por ele instituído, a saber:

[...] o desenvolvimento da cultura geral, o incremento das indústrias, o progresso das artes, o progresso das letras, o progresso científico, a vitalidade do comércio interno, a riqueza do comércio externo, a paz política, a elevação do nível de riqueza e bemestar (SCHWARCZ, 2002, p. 96 apud SAVIANI, 2007, p. 81). 


\section{Linguagens - Revista de Letras, Artes e Comunicação - ISSN 1981- 9943 \\ Blumenau, v. 12, n. 3, p. 415-435, set./dez. 2018. \\ DOI: http://dx.doi.org/10.7867/1981-9943.2018v12n3p415-435}

O Alvará de 1759 instituiu a abertura de classes gratuitas de gramática latina em Lisboa e a distribuição de professores de grego, tanto na capital como nas cidades de Porto, Évora e Coimbra. Em anexo ao Alvará, “instruções para os professores de Gramática Latina, Grega, Hebraica, e de Retórica” traziam as seguintes determinações, entre outras - algumas das quais soam, hoje, ultrapassadas, outras que parecem modernas, e outras que permanecem controversas (SAVIANI, 2007, p. 83-88):

- “deve ser em vulgar o método para aprender os preceitos da Gramática, pois não há maior absurdo que intentar aprender uma língua, no mesmo idioma que se ignora";

- " "o método deve ser breve, claro e fácil, para não atormentar aos estudantes";

- $\quad$ é útil "lançar mão das noções da língua portuguesa, mostrando a analogia com a latina para que os alunos percebam com mais facilidade os princípios da gramática latina";

- $\quad$ a repetição é importante para estabelecer os rudimentos da matéria estudada entretanto, "a prática de recitar versos de cor, confusamente e sem escolha", deve ser substituída pela recitação de passagens, em prosa ou verso, "nas quais haja alguma coisa útil e deleitável que possa, ao mesmo tempo, servir-lhes de exercício e de instrução";

- os temas das composições lidas em latim devem progredir dos mais fáceis aos mais difíceis;

- a prática de falar em latim durante as aulas deve ser evitada, por não ter utilidade alguma;

- as obras lidas em grego devem conter apenas o original, evitando-se versões bilíngues grego-latim, a fim de garantir que os alunos leiam em grego.

Um único parágrafo da Lei trata do estudo da língua hebraica, o que é compreensível na medida em que as disposições sobre esse estudo costumavam ser responsabilidade de Ordens religiosas (SAVIANI, 2007, p. 83-88).

Também data do ano de 1759 a primeira tentativa de imposição da língua portuguesa no Brasil, ficando proibido o uso de outras línguas nas colônias portuguesas (KERSCH; SAUER, 2010, p. 189; SOARES, 2002). A partir daí o Nheengatu perdeu o status de lingua franca que mantinha até então, quando servia à comunicação entre nativos brasileiros, portugueses e africanos escravizados (FRITZEN, 2007, p. 129).

No Brasil, os primeiros concursos para admissão de professores foram realizados em 1760. Após a reforma da Universidade de Coimbra, a Lei de 6 de novembro de 1772 determinou a distribuição das aulas régias pelo reino de Portugal e suas colônias, ficando distribuídas as aulas no Brasil conforme a Tabela 1:

Tabela 1. Distribuição das aulas conforme a Lei de 6 de novembro de 1772 
Linguagens - Revista de Letras, Artes e Comunicação - ISSN 1981- 9943

Blumenau, v. 12, n. 3, p. 415-435, set./dez. 2018.

DOI: http://dx.doi.org/10.7867/1981-9943.2018v12n3p415-435

\begin{tabular}{|l|c|c|c|c|c|}
\hline & Ler, escrever, contar & Latim & Grego & Retórica & Filosofia \\
\hline Rio de Janeiro & 2 & 2 & 1 & 1 & 1 \\
Bahia & 4 & 3 & 1 & 1 & 1 \\
Pernambuco & 4 & 4 & 1 & 1 & 1 \\
Mariana & 1 & 1 & - & 1 & - \\
São Paulo & 1 & 1 & - & 1 & - \\
Vila Rica & 1 & 1 & - & - & - \\
S. J. del Rei & 1 & 1 & - & - & - \\
Pará & 1 & 1 & - & 1 & - \\
Maranhão & 1 & 1 & - & - & - \\
\hline Total & 16 & 15 & 3 & 6 & 3 \\
\hline
\end{tabular}

Fonte: organizado por Cardoso (2002, p. 155, citado por SAVIANI, 2007, p. 97)

Nota-se que as línguas clássicas eram dotadas de grande prestígio, sendo o acesso a aulas dessas línguas, portanto, um privilégio destinado a uma elite. Quanto ao método de ensino de línguas empregado à época, é conhecido hoje como Método de Gramática e Tradução: consistia na apresentação de um tópico gramatical, na produção de frases que mobilizassem esse tópico e, por fim, na elaboração de traduções e versões de trechos de obras literárias. Desse modo, as lições eram organizadas por tópicos gramaticais, e a aprendizagem ocorria por meio da memorização mecânica de regras gramaticais e listas de vocabulário. Também havia exercícios de ditado, elaboração de resumos e escrita livre, mas o grande foco da aprendizagem de outras línguas era o acesso aos bens culturais produzidos nas línguas de prestígio, como pilar da formação espiritual do aprendiz. As aulas eram ministradas em língua materna, e a correção gramatical era fundamental (cf. NEUNER; HUNFELD, 1993).

\subsection{SÉCULOS XIX E XX: DA REVOLUÇÃO INDUSTRIAL À DESINDUSTRIALIZAÇÃO}

As reformas pombalinas do século XVIII, baseadas nas ideias laicas inspiradas no Iluminismo, instituíram a prerrogativa do Estado em relação à instrução (SAVIANI, 2007, p. 114). A organização do ensino no Brasil permaneceu pautada pelas orientações dessas reformas até meados do século XIX, até que chegaram no ensino brasileiro os primeiros efeitos da Revolução Industrial iniciada na Europa: já não fazia sentido ensinar uma língua viva da mesma forma como se ensinava o grego e o latim, línguas mortas, pois esse método não preparava os aprendizes para as situações cada vez mais comuns de uso real da língua-alvo.

Assim, as críticas ao Método de Gramática e Tradução, iniciadas décadas antes, ganharam mais espaço. Surgia o Método Direto para o ensino de línguas: opondo-se a seu antecessor, defendia aulas monolíngues, a fim de que o aprendiz atingisse o domínio oral da 


\section{Linguagens - Revista de Letras, Artes e Comunicação - ISSN 1981- 9943 \\ Blumenau, v. 12, n. 3, p. 415-435, set./dez. 2018. \\ DOI: http://dx.doi.org/10.7867/1981-9943.2018v12n3p415-435}

língua, através da indução, isto é, da imitação, tendo o professor como principal modelo. $\mathrm{O}$ nome método direto - também método antigramatical, método de reforma, método racional, método natural, método concreto, método intuitivo ou método analítico (NEUNER; HUNFELD, 1993, p. 33) - faz referência ao objetivo de oferecer ao aprendiz uma experiência autêntica de aquisição de língua, através da exposição a situações equivalentes ao cotidiano, de modo semelhante à de aquisição de língua materna pelas crianças pequenas. $\mathrm{O}$ foco, portanto, já não era o contato com obras literárias, mas a formação integral do aprendiz para lidar com as mais diversas situações do cotidiano.

Outro grande marco do século XIX foi o início dos grandes fluxos de imigração para o Brasil. Os primeiros alemães chegaram a São Leopoldo, no Rio Grande do Sul, em 1824; cinco décadas depois, teve início a imigração italiana, e a japonesa, no ano de 1908, sendo essas três as mais significativas para o desenvolvimento econômico do país naquela época.

Silva (2015) afirma que o ensino oficial de línguas estrangeiras modernas nas escolas brasileiras teve início em 1837: além do latim e do grego, tornaram-se obrigatórios o inglês, o francês e o alemão. Em 1915, o grego foi abolido das escolas, e a partir de 1930, permaneceu obrigatório o ensino de inglês e francês, totalizando 17 horas semanais de língua estrangeira (SILVA, 2015). O francês começou a perder prestígio para o inglês a partir da chegada do cinema falado, na década de 1920, e esse processo se intensificou após a Segunda Guerra Mundial, com o aumento da "dependência econômica e cultural brasileira em relação aos Estados Unidos” (SILVA, 2015). A partir daí, à medida que o inglês conquistava espaço, o ensino de outras línguas sofreu um declínio.

Também na década de 1920 surgiu o Método Audiolingual, trazendo influências diretas tanto da Psicologia Behaviorista ou comportamental como da Linguística Estruturalista, que adota a análise descritiva, sincrônica e indutiva do sistema de formas de cada língua. O método teve seu auge nas décadas de 1950 e 1960, em decorrência de uma ordem mundial pautada pela “aproximação e cooperação entre vários países forçadas pela II Guerra Mundial e pelo advento da Guerra Fria” (MEIRELES, 2002, p. 154).

Tendo como objetivo principal o uso da língua falada e como principal gênero discursivo o diálogo, assim como seu antecessor, o Método Direto, o Audiolingual incluiu nas aulas alguns procedimentos da análise estruturalista. Um exemplo dessa influência são os exercícios em que há modelos de frases a serem modificados pelo aprendiz, além da memorização e representação de modelos de diálogos. A análise das estruturas linguísticas servia como fundamento para a produção de materiais didáticos, isto é, a progressão desses materiais seguia a complexidade dos tópicos trabalhados. As aulas eram baseadas em reproduzir 


\section{Linguagens - Revista de Letras, Artes e Comunicação - ISSN 1981- 9943 \\ Blumenau, v. 12, n. 3, p. 415-435, set./dez. 2018. \\ DOI: http://dx.doi.org/10.7867/1981-9943.2018v12n3p415-435}

e modificar ligeiramente longos diálogos prontos, sendo as frases-modelo [pattern drills] destinadas a automatizar o conteúdo gramatical trabalhado.

Como desdobramento do Audiolingual, surgiu o Método Audiovisual, refletindo a modernização dos materiais que chegavam à sala de aula, tais como slides e vídeos. Os recursos visuais, entretanto, não chegavam a alterar a proposta audiolingual: as aulas de língua permaneciam pautadas na exibição de imagens e de um diálogo gravado, o qual deveria ser memorizado e, por fim, modificado, antes de proceder à repetição dos pattern drills.

Na mesma época, mais precisamente em 1961, foi sancionada a primeira Lei que estabeleceria as Diretrizes e Bases da Educação Nacional, conhecida como LDB (BRASIL, 1961). Silva (2015, s/p) afirma que, "enquanto o prestígio da língua inglesa crescia na sociedade brasileira, a LDB de 1961 retirou a obrigatoriedade do ensino de línguas estrangeiras no ensino médio, deixando a cargo das escolas a sua inclusão nos currículos". O efeito dessa medida, justamente quando o inglês já tinha adquirido sólida popularidade, fez crescer significativamente o número de cursos livres de idiomas no Brasil, contribuindo para instaurar a ideia de que não se aprende inglês na escola (PAIVA, 2003, p. 56).

Quanto aos aspectos econômicos relacionados à política linguística brasileira, Paulani (2012, p. 90) lembra que, até o início do século XX, o Brasil tinha a função de produzir bens primários, de baixo valor agregado, garantindo assim a acumulação capitalista nos países centrais. Nos anos 1950, “acossado já pelo problema da sobreacumulação, o capital do Centro do sistema vai encontrar na economia brasileira [...] o mercado que começava a escassear no mundo desenvolvido" (PAULANI, 2012, p. 90). Porém, essa possibilidade de que o Brasil trocasse a dependência dos países centrais pela autonomia não se concretizou, devido à crise deflagrada nos anos 1970; aí teve início “aquilo que viria a ser chamado de 'financeirização', indicando um processo em que a acumulação se dá sob os imperativos e a lógica da valorização financeira" (PAULANI, 2012, p. 91).

Esse novo regime de acumulação, que aumentou a demanda por empréstimos no país, levaria a duas décadas de estagnação econômica. A consequência desse período de estagnação, nas palavras de Paulani (2012, p. 91), foi a "completa submissão de sua política econômica às exigências dos credores, em outras palavras a adoção do discurso e da prática neoliberais". Assim, o Brasil foi de economia periférica industrializada a economia financeirizada em processo de desindustrialização, "asfixiando a retomada sustentada do desenvolvimento nacional" a partir da combinação entre a estabilidade monetária produzida pelo Plano Real e a valorização dos ativos financeiros (POCHMANN, 2007, p. 1478). 


\section{Linguagens - Revista de Letras, Artes e Comunicação - ISSN 1981- 9943 \\ Blumenau, v. 12, n. 3, p. 415-435, set./dez. 2018.}

DOI: http://dx.doi.org/10.7867/1981-9943.2018v12n3p415-435

Enquanto isso, uma nova formulação da LDB reduzia um ano da escolaridade obrigatória - o que, naturalmente, teve impacto negativo sobre a carga horária de ensino de línguas (BRASIL, 1971). Silva (2015, s/p) observa que, "nesse documento, o ensino de língua estrangeira continuou a ser desvalorizado, visto que era recomendável, e não obrigatório". A mesma LDB de 1971 determinou que a língua portuguesa passasse a funcionar como instrumento a serviço do desenvolvimento do Brasil (ESPÍRITO SANTO; SANTOS, 2018, p. 156), num discurso típico da ditadura militar.

Portanto, o cenário de desvalorização das línguas estrangeiras nas escolas brasileiras só começou a se modificar a partir da Resolução $n^{\circ} 58$ de 1976, que estabeleceu a obrigatoriedade do ensino de uma língua estrangeira no $2^{\circ}$ grau, isto é, no Ensino Médio (BRASIL, 1976); passaram-se vinte anos até que uma nova LDB fosse sancionada, tornando obrigatório o ensino de uma língua estrangeira a partir da quinta série do Ensino Fundamental, além do ensino de uma segunda língua de forma optativa no Ensino Médio (BRASIL, 1996).

Também foi somente na década de 1970 que o ensino das línguas de imigração - isto é, das línguas faladas por imigrantes nas regiões onde estes se concentravam - passou a ser reinserido nas redes públicas de ensino, após ter sido proibido pela Constituição de 1934 (BRASIL, 1934; CAMPOS, 2006; KERSCH; SAUER, 2010; UPHOFF, 2011).

Enquanto isso, diversificava-se o público que buscava aulas de outras línguas, privilégio até então reservado a uma elite global. Os novos aprendizes de línguas formavam grupos heterogêneos em relação a idade, conhecimento de mundo e objetivos que pretendiam alcançar por meio da nova língua. Para atender aos diferentes objetivos dos aprendizes, começaram a surgir modelos híbridos de aula, que traziam características do Método Audiolingual/Audiovisual mescladas com o Método de Gramática e Tradução; tal estratégia que ficou conhecida em alguns países como Método Intermediário (cf. NEUNER; HUNFELD, 1993). A sequência das aulas era orientada pela progressão gramatical, e o uso da língua-alvo em sala de aula não se restringia aos exercícios de repetição.

Portanto, em meados da década de 1970, já se entendia que não seria possível descobrir “o melhor" método de ensino de línguas. As novas propostas para o ensino de línguas passaram a ser denominadas 'orientações' ou 'abordagens' (RÖSLER, 2012, p. 76). É dessa época o surgimento da abordagem comunicativa, a partir da chamada virada pragmática (RÖSLER, 2012, p. 76); que é quando, nas palavras de Meireles (2002, p. 156, grifo nosso), “o sistema linguístico é visto como um instrumento de interação humana, sendo que as formas e estruturas linguísticas devem ser transmitidas em seu significado funcional". Desse modo, tanto a erudição pretendida pelo Método de Gramática e Tradução como o foco dado à gramática pelo 


\section{Linguagens - Revista de Letras, Artes e Comunicação - ISSN 1981- 9943 \\ Blumenau, v. 12, n. 3, p. 415-435, set./dez. 2018. \\ DOI: http://dx.doi.org/10.7867/1981-9943.2018v12n3p415-435}

Método Audiolingual seriam substituídos por uma concepção de aprendizagem focada no cotidiano.

Almeida Filho (2001, p. 25-26) resume da seguinte forma as principais características da abordagem: não se trata de abolir a gramática nem de focar necessariamente na oralidade, e sim de superar a ideia de aprender língua pela língua, substituindo-a pela ideia de aprender outras coisas naquela língua, aprendendo também a língua nesse ambiente.

Quando a abordagem comunicativa já estava estabelecida sobre o conceito pragmáticofuncional, na metade da década de 1980, surgiram novos questionamentos: qual seria a utilidade de aprender línguas, sobretudo com foco na 'comunicação cotidiana', se nem todos os aprendizes tinham a pretensão de viajar para outros países? E mais: qual o objetivo de aprender línguas em um mundo de mudanças cada vez mais rápidas? (cf. NEUNER; HUNFELD, 1993, p. 87). Surgia então o conceito cultural da didática comunicativa, conferindo especial atenção à Linguística Textual e à recepção de textos literários a partir do ponto de vista do estrangeiro. Esse processo daria origem a uma nova abordagem: a intercultural.

Característica de uma época de crescente mobilidade, devido à expansão da globalização e à unificação de estados em economias de concorrência, a abordagem intercultural ampliou os antigos focos da aula de língua na correção gramatical e na fluência oral para abranger princípios como democracia, respeito à diversidade e formação da identidade do aprendiz - ao mesmo tempo, o inglês se consolidava como língua franca.

Dessa forma, os métodos de ensino de línguas perdiam cada vez mais prestígio, e começava a se falar em uma Era Pós-Método (PRABHU, 1990; ALLWRIGHT, 1991; KUMARAVADIVELU, 1994, 2001, 2003, 2006). Kumaravadivelu (2006, p. 163-168) chegou a elencar cinco famosos 'mitos' dos métodos de ensino de línguas, para a seguir desconstruílos um a um. São eles:

- o mito de que existe um método melhor, pronto para ser descoberto;

- o mito de que o método constitui o princípio organizador do ensino de línguas;

- o mito de que o método tem um valor universal e a-histórico;

- o mito de que teóricos produzem conhecimento, e professores apenas o consomem;

- o mito de que o método é neutro e não contém motivações ideológicas.

Segundo Leffa (2005, p. 203), a ênfase na questão metodológica parte do princípio de que a aprendizagem de uma língua estrangeira depende da metodologia usada pelo professor, enquanto uma ênfase na questão política concernente ao ensino de línguas reconheceria o papel do professor de mostrar novas perspectivas aos alunos, levando a uma apreciação da língua do outro e a um convívio democrático com a diversidade. Fogaça e Gimenez (2007, p. 173) 


\title{
Linguagens - Revista de Letras, Artes e Comunicação - ISSN 1981- 9943 \\ Blumenau, v. 12, n. 3, p. 415-435, set./dez. 2018. \\ DOI: http://dx.doi.org/10.7867/1981-9943.2018v12n3p415-435
}

também destacam a necessidade de professores e alunos entenderem o mundo em que vivem para construir uma educação transformadora.

Enquanto isso, no Brasil, a LDB nº 9.394, de 1996, determinava a obrigatoriedade de uma língua estrangeira moderna a partir do segundo ciclo do Ensino Fundamental, isto é, da quinta série à época, conforme escolha da comunidade; no Ensino Médio, haveria a possibilidade de oferta de uma segunda língua estrangeira, em caráter optativo, conforme as possibilidades de cada instituição. Ao mesmo tempo em que essa lei representou um passo para a retomada da valorização do ensino de línguas na escola, no momento em que a popularidade do inglês atingia seu auge, ela apresentou também algumas controvérsias. A principal delas foi a ausência de regulamentação do ensino de línguas estrangeiras na Educação Infantil e nos dois primeiros ciclos do Ensino Fundamental, isto é, da primeira à quarta série.

O Sindicato dos Profissionais em Educação no Ensino Municipal de São Paulo (SINPEEM) divulgou o seguinte comentário à LDB de 1996:

\begin{abstract}
A Lei ${ }^{0}$ 5.692/71 expressou a necessidade de expansão quantitativa do mercado de trabalho e provocou uma explosão demográfica na educação. Reduziu-se a escolarização aos limites das necessidades de mercado, cabendo ao aluno aprender os níveis elementares de leitura, escrita e cálculo, suscitando inúmeras críticas ao aumento da quantidade de matrículas em detrimento da qualidade do ensino. Naquela época, o objetivo da ditadura militar era transformar a educação em qualificação para o trabalho e atender às necessidades impostas pelo desenvolvimento econômico. Hoje, com a reorganização do processo produtivo, a expansão do mercado de trabalho é qualitativa. Com o avanço tecnológico está ocorrendo uma redução na quantidade de empregos e ampliando as exigências de qualificação de quem está na ativa, provocando o aumento da população excluída do processo produtivo (SINPEEM, 2003, s/p).
\end{abstract}

Percebe-se nesse trecho a consciência de que o ensino escolar já se encontrava submetido às exigências do mercado e, portanto, do capital financeiro, assim como os primeiros indícios da era tecnológica que haveria de exigir qualificações cada vez mais altas a fim de atender às demandas desse mesmo mercado.

As línguas estão entre as áreas do conhecimento mais afetadas por esse processo, já que o professor sistematicamente é destituído de agência política, conforme discute Leffa (2005), mencionado anteriormente. Silva $(2015, \mathrm{~s} / \mathrm{p})$ também observa que o professor de línguas não é incentivado a refletir sobre questões pertinentes à profissão docente e aos "diferentes métodos, técnicas e teorias"; antes disso, "é condicionado a preocupar-se com o modo de colocar tudo isso em prática de maneira acrítica".

Diante desse cenário, o século XX chegou ao fim. A próxima seção se ocupa das duas décadas que a ele se seguiram. 


\section{Linguagens - Revista de Letras, Artes e Comunicação - ISSN 1981- 9943 \\ Blumenau, v. 12, n. 3, p. 415-435, set./dez. 2018. \\ DOI: http://dx.doi.org/10.7867/1981-9943.2018v12n3p415-435}

\subsection{SÉCULO XXI: PCN, OCEM, BNCC}

Os Parâmetros Curriculares Nacionais (PCN) para o Ensino Fundamental (EF) foram publicados pela primeira vez em 1998, a fim de embasar as políticas de ensino e aprendizagem nas escolas brasileiras, a partir do estudo das propostas curriculares de estados e municípios brasileiros e de outros países (SILVA, 2015). Guedes (2002, p. 88) lembra que o estabelecimento dos PCN correspondeu às exigências do Plano Decenal de Educação para Todos (1993-2003), “que, em consonância com a Constituição de 1988, afirma a necessidade e a obrigação de o Estado elaborar parâmetros para orientar as ações educativas”. Porém, já na etapa de elaboração, foram excluídos do processo os alunos e os professores, o que influenciou nas subsequentes etapas de adaptação dos Parâmetros pelos Estados e de adequação das escolas e dos professores a esses parâmetros: "por que os professores não puderam ser autores, mas são obrigados a ser executores?" (GUEDES, 2002, p. 89).

Em relação aos PCN de Língua Estrangeira, consta no documento a afirmação de que, "primordialmente, objetiva-se restaurar o papel da Língua Estrangeira na formação educacional" (BRASIL, 1998, p. 19). O foco do documento na competência de leitura gerou controvérsias; porém, ao lado dos diversos fatores que embasam essas controvérsias, temos visto aqui o quão inviável seria desenvolver as quatro habilidades com uma carga horária tão baixa para as línguas no currículo escolar.

Já os Parâmetros Curriculares Nacionais para o Ensino Médio (PCNEM), tanto em sua versão inicial (BRASIL, 1999) quanto em sua expansão, as Orientações Educacionais Complementares aos Parâmetros Curriculares Nacionais, popularmente denominadas PCN+ Ensino Médio, foram considerados ineficazes no sentido de servir como orientação para a elaboração de currículos, pois definiam os conteúdos e métodos de forma hermética (SILVA, 2015).

Em 2005, foi sancionada a lei conhecida como 'lei do espanhol', que tornou a oferta da língua espanhola facultativa a partir da antiga quinta série do Ensino Fundamental e obrigatória no Ensino Médio, no horário regular de aula, embora a matrícula fosse facultativa para os alunos (BRASIL, 2005). É interessante notar que essa medida foi a primeira a definir uma língua específica a ser ensinada na escola, pois a LDB então vigente estipulava apenas a oferta de "uma língua estrangeira moderna" à escolha da comunidade (BRASIL, 1996). 


\section{Linguagens - Revista de Letras, Artes e Comunicação - ISSN 1981- 9943 \\ Blumenau, v. 12, n. 3, p. 415-435, set./dez. 2018. \\ DOI: http://dx.doi.org/10.7867/1981-9943.2018v12n3p415-435}

Em 2006 foram criadas as Orientações Curriculares para o Ensino Médio (OCEM), a fim de aprofundar as propostas dos PCN. As OCEM para Línguas Estrangeiras apresentam cinco objetivos, bastante relevantes e alinhados com os desafios da contemporaneidade:

- retomar a reflexão sobre a função educacional do ensino de Línguas Estrangeiras no ensino médio e ressaltar a importância dessas;

- reafirmar a relevância da noção de cidadania e discutir a prática dessa noção no ensino de Línguas Estrangeiras;

- discutir o problema da exclusão no ensino em face de valores "globalizantes" e o sentimento de inclusão frequentemente aliado ao conhecimento de Línguas Estrangeiras;

- introduzir as teorias sobre a linguagem e as novas tecnologias (letramentos, multiletramentos, multimodalidade, hipertexto);

- dar sugestões sobre a prática do ensino de Línguas Estrangeiras por meio dessas (BRASIL, 2006, p. 87).

O documento reforça a LDB de 1996 ao propor uma organização curricular para o Ensino Médio e destacar suas finalidades, mas esclarece que "cabe à equipe docente analisar e selecionar os pontos que merecem aprofundamento" (BRASIL, 2006, p. 9). O volume dedicado às linguagens e suas tecnologias abrange, em seis capítulos, as áreas de língua portuguesa, literatura, línguas estrangeiras, espanhol, arte e educação física.

A princípio, surpreende o fato de o espanhol ser tratado em separado das "línguas estrangeiras", mas tal medida está de acordo com a lei que torna obrigatória a oferta do espanhol, conforme explicitado na própria introdução do capítulo (BRASIL, 2006, p. 127). Enquanto o capítulo sobre línguas em geral trata do papel do ensino de línguas com relação aos conceitos de cidadania, inclusão e letramento, o capítulo dedicado ao espanhol vai além dos objetivos e conteúdos para o ensino da língua nas escolas, abordando especificidades como as variedades da língua espanhola e os efeitos da proximidade com o português.

Segundo as OCEM (BRASIL, 2006, p. 89-90), surge um conflito de objetivos do ensino de línguas na educação básica "quando a escola regular tende a concentrar-se no ensino apenas linguístico ou instrumental", desconsiderando objetivos educacionais e culturais para manter em foco o conteúdo em si. No capítulo dedicado aos conhecimentos de espanhol, consta a afirmação de que "a função maior de uma língua estrangeira no contexto escolar é a de contribuir para a formação do cidadão (BRASIL, 2006, p. 146).

Por fim, foi lançada em 2017 a Base Nacional Comum Curricular (BNCC). As linguagens abordadas pelo documento, tanto para o Ensino Fundamental como para o Ensino Médio, são a arte, a educação física e as línguas portuguesa e inglesa (BRASIL, 2017a). 


\section{Linguagens - Revista de Letras, Artes e Comunicação - ISSN 1981- 9943 \\ Blumenau, v. 12, n. 3, p. 415-435, set./dez. 2018. \\ DOI: http://dx.doi.org/10.7867/1981-9943.2018v12n3p415-435}

Lamentavelmente, no mesmo ano, foi revogada em definitivo a lei do espanhol, após medida provisória nesse sentido promulgada no ano anterior (BRASIL, 2017b). A lei $\mathrm{n}^{\mathrm{o}} 13.415$ estabeleceu o inglês como língua obrigatória a ser ofertada no Ensino Fundamental a partir do sexto ano, antiga quinta série, e no Ensino Médio, retirando da comunidade escolar a autonomia na escolha da língua - e também transformou a oferta obrigatória do espanhol no Ensino Médio na oferta opcional de outras línguas, "preferencialmente o espanhol”, mas de matrícula optativa.

Desse modo, o ensino de línguas no Brasil, após décadas de desvalorização e um breve reflorescimento com a LDB de 1996 e a lei do espanhol de 2005, voltou a regredir. Mais uma vez, o estudante brasileiro teria a oportunidade de aprender uma única língua adicional na escola, e obrigatoriamente o inglês. A seguir, aprofundaremos a reflexão sobre as implicações dessa medida.

\section{AS LÍNGUAS NOS DOCUMENTOS QUE REGEM O ENSINO E A EDUCAÇÃO A SERVIÇO DO MERCADO}

Já mencionamos aqui alguns dos efeitos do neoliberalismo sobre o ensino de línguas no Brasil: a ideia de que não se aprende línguas na escola, o consequente crescimento dos cursos de línguas privados, o posicionamento tradicionalmente acrítico dos professores de línguas. Essa ideologia fortaleceu a compreensão de que o ensino de línguas, como o de outras disciplinas, tem como objetivo servir ao mercado financeiro, isto é, a finalidade de aprender línguas seria conseguir destaque no mercado de trabalho.

Hoje, em grande parte devido a essa visão limitada dos objetivos de aprender uma língua, o inglês é a única língua de oferta obrigatória no sistema escolar brasileiro. Para efeitos ilustrativos do declínio do ensino de línguas ao longo do século $\mathrm{XX}$, podemos comparar essa situação com a de 1870: segundo o Plano de Estudos do Colégio Abílio do Rio de Janeiro naquela década, estudava-se francês nos três anos de instrução primária, e latim, francês, inglês e alemão distribuídos ao longo dos sete anos de instrução secundária (SAVIANI, 2007, p. 143145).

Com o passar do tempo, não só diminuiu a quantidade de línguas ensinadas nas escolas, mas também se alteraram muito as concepções de língua e de sujeito que permeiam esse ensino. Até o início do século XIX, o intuito de se aprender grego e latim era atingir uma formação intelectual e moral elevada; com a Revolução Industrial e o Método Direto, já pensado para o ensino de línguas vernáculas, o propósito passou a ser a comunicação em situações cotidianas; 


\section{Linguagens - Revista de Letras, Artes e Comunicação - ISSN 1981- 9943 \\ Blumenau, v. 12, n. 3, p. 415-435, set./dez. 2018. \\ DOI: http://dx.doi.org/10.7867/1981-9943.2018v12n3p415-435}

a proposta do Método Audiolingual, em conformidade com as recentes descobertas da Linguística à época, veio a calhar em um período marcado por guerras, pois havia urgência em adquirir as habilidades de compreender e se expressar na língua do oponente. Os métodos híbridos e as novas abordagens de ensino que se seguiram procuraram levar em conta a multiplicidade de fatores individuais e sociais que coexistem dentro do ambiente escolar. Deste modo, abriu-se espaço para uma reflexão acerca do papel do professor de línguas, que, enquanto confinado a métodos fechados, não dispunha de oportunidades de exercer de forma crítica o ofício docente.

Porém, na contramão desse avanço no ensino de línguas do ponto de vista intelectual, sobreveio a onda neoliberal no Brasil, relegando a segundo plano a reflexão crítica sobre o papel das múltiplas linguagens como parte da formação escolar - e atropelando, assim, os objetivos para o ensino de línguas expressos nas OCEM - para restringir-se às línguas, ou à língua, de maior prestígio no mercado de trabalho global.

A ausência de clareza sobre os objetivos do ensino de línguas na escola (BRASIL, 2006, p. 90) era o ingrediente que faltava para que se comprasse a ideia neoliberal de que não se aprende línguas na escola, semeada desde a LDB de 1961. Assim, ao esperar que o ensino de línguas na escola prepare o aluno para lidar com determinadas situações encontradas no mercado de trabalho, envolvendo uma gama específica de competências a serem desenvolvidas, a sociedade conclui que a escola falhou. Como consequência, parte-se para cursos de línguas em instituições privadas, o que garante o cumprimento de duas das maiores premissas do neoliberalismo.

Em primeiro lugar, tem-se o redirecionamento da clientela dos serviços públicos, custeados pelos impostos de todos, à iniciativa privada, restrita àqueles que podem pagar a mais pelos mesmos serviços. Pochmann (2007, p. 1479) aponta que um dos efeitos do avanço da riqueza financeirizada foi justamente o achatamento da renda dos trabalhadores, o que significa que a maior parte desses trabalhadores não tem acesso aos serviços prestados pela iniciativa privada. Em segundo lugar, tem-se a formação com o único objetivo de servir ao mercado de trabalho - em estratégia análoga àquela utilizada durante a Ditadura Militar, conforme observação do SINPEEM supracitada.

Note-se também que, quanto mais avançadas as concepções de língua que moldaram os métodos e abordagens de ensino de línguas ao longo das décadas, menor a oferta de línguas no ensino público brasileiro. Enquanto as mais recentes descobertas no campo da linguística, da psicologia e da sociologia servem ao desenvolvimento de novas formas de ensinar, a frágil democracia brasileira regula o acesso à aprendizagem, restringindo o pensamento de modo 


\section{Linguagens - Revista de Letras, Artes e Comunicação - ISSN 1981- 9943 \\ Blumenau, v. 12, n. 3, p. 415-435, set./dez. 2018. \\ DOI: http://dx.doi.org/10.7867/1981-9943.2018v12n3p415-435}

semelhante àquele empregado durante a Ditadura Militar ao valer-se da lógica neoliberal para garantir que o conhecimento permaneça um privilégio destinado a uma pequena parte da população.

Conforme vimos, os principais documentos que estabelecem hoje as diretrizes do ensino no Brasil, em conformidade com a LDB, são os PCN, as OCEM e a nova Base Nacional Comum Curricular. Nos dois primeiros documentos, Fogaça e Gimenez (2007) identificam traços de duas visões de educação. A mais constante delas é a educação como redenção, como forma de estabelecer harmonia entre os membros da sociedade. A segunda, presente em conceitos-chave como "ensino que desperte a consciência crítica para as diferentes visões de mundo expressas na e pela linguagem", segundo as OCEM (BRASIL, 2006, p. 176), é a educação transformadora.

Em uma primeira análise, pode parecer difícil diferenciar a tendência redentora e a tendência transformadora, mas enquanto aquela procura manter a harmonia promovendo oportunidades aos grupos marginalizados, esta propõe a total abolição dos fatores que geram grupos marginalizados. A esse respeito, Young (2008, p. 9) observa que a globalização e o imperialismo se refletem nos currículos educacionais na medida em que os grupos subordinados não dispõem de recursos para enfrentar os grupos dominantes, e que seria necessário desenvolver uma teoria não colonizadora do conhecimento para embasar sugestões de mudanças em direção a um sistema menos discriminatório.

Em resumo, "uma teoria crítica, transformadora, deveria ser formulada do ponto de vista dos interesses dos dominados, já que a classe dominante pretende apenas acionar mecanismos de adaptação que evitem a transformação" (FOGAÇA; GIMENEZ, 2007, p. 173). Afinal, se o ensino de línguas no Brasil voltou a regredir após um breve período de crescimento, compreendido entre a promulgação da LDB de 1996 e a revogação da lei do espanhol em 2017, é hora de fazer valer o objetivo explicitado nos PCN de restaurar o papel das línguas na formação educacional, retomando a reflexão sobre a função educacional do ensino de línguas no ensino médio e ressaltando sua importância, conforme objetivo das OCEM.

\section{CONCLUSÃO}

Neste trabalho, procuramos apresentar os efeitos das políticas linguísticas para o ensino de línguas no Brasil ao longo da história. Ainda que a desvalorização do ensino de línguas tenha iniciado décadas antes, a lógica neoliberal se encontra hoje indiscutivelmente impregnada aí: 


\section{Linguagens - Revista de Letras, Artes e Comunicação - ISSN 1981- 9943 \\ Blumenau, v. 12, n. 3, p. 415-435, set./dez. 2018.}

DOI: http://dx.doi.org/10.7867/1981-9943.2018v12n3p415-435

não se reconhece finalidades outras para aprendê-las que não o sucesso no mercado de trabalho, de modo que este vem ditando o ritmo daquilo que se faz na escola.

Compreendemos que, quanto mais fechado o regime de governo no país, maior o controle sobre a distribuição linguística. Isso nos leva à conclusão de que o neoliberalismo é, acima de tudo, um governo de extremo controle da sociedade - afinal, a oferta de línguas na educação básica fica restrita, no regime neoliberal, às línguas e aos métodos de mensuração do conhecimento que servem às necessidades do mercado de trabalho, em detrimento da formação plurilíngue e pluricultural que deveria ser um dos objetivos do ensino de línguas nas escolas.

O professor, privado de sua autonomia desde a época em que era encarregado unicamente de reproduzir métodos - constituindo o mito do professor que apenas consome o conhecimento produzido por teóricos, sem ter as competências necessárias para produzi-lo permanece de mãos atadas diante da obrigatoriedade de ensinar línguas hegemônicas, a partir de uma perspectiva colonizadora, com base em objetivos determinados por agentes que não têm, em absoluto, a preocupação de formar cidadãos conscientes para conviver cada vez mais com as diversidades.

É importante salientar que não nos colocamos contra o ensino de línguas hegemônicas nas escolas brasileiras. Ir contra a oferta de uma qualificação que favoreça a inserção da juventude no mercado de trabalho seria um posicionamento totalmente desconectado da realidade da nossa população, já fadada a lutar bravamente por condições de vida minimamente dignas. Muito pelo contrário: defendemos que o ensino de línguas nas escolas tenha um caráter efetivamente educativo, transcendendo a instrumentalidade para abrir espaço para abordagens de ensino pautadas pela interculturalidade, que façam jus tanto às pesquisas na área de ensino e aprendizagem de línguas como à realidade globalizada em que vivemos.

Uma tal mudança de perspectiva restituiria a autonomia do professor, que deixaria de ser um mero aplicador de métodos antiquados ou de técnicas tidas como modernas para tornarse um agente da educação, um ator social, um educador no mais pleno sentido da palavra, essa profissão tão ingrata em tempos de fomento institucionalizado à ignorância.

\section{REFERÊNCIAS}

ALLWRIGHT, D. The death of the method. Lancaster: The Exploratory Practice Centre/University of Lancaster, 1991.

ALMEIDA FILHO, J. C. P. O Ensino de Línguas no Brasil de 1978. E Agora? Revista

Brasileira de Linguística Aplicada, Belo Horizonte, v. 1, n. 1, p. 15-29, 2001. 
AUROUX, S. A revolução tecnológica da gramatização. Trad. de ORLANDI, E. P. Campinas: Editora da Unicamp, 1992.

BRASIL. Base Nacional Comum Curricular (BNCC). MEC, 2017a. Disponível em: $<$ http://basenacionalcomum.mec.gov.br/images/BNCC_EI_EF_110518_versaofinal_site.pdf $>$ . Acesso em: 21 abr. 2018.

BRASIL. Constituição da República dos Estados Unidos do Brasil (de 16 de julho de 1934). Disponível em:

$<$ http://www.planalto.gov.br/ccivil_03/constituicao/constituicao34.htm>. Acesso em: 10 jun. 2018.

BRASIL. Lei no 4.024, de 20 de dezembro de 1961. Fixa as Diretrizes e Bases da Educação Nacional. Brasília, DF: 1961. Disponível em:

$<$ http://www.planalto.gov.br/ccivil_03/LEIS/L4024.htm>. Acesso em: 10 jun. 2018.

BRASIL. Lei no 5.692, de 11 de agosto de 1971. Fixa Diretrizes e Bases para o ensino de $1^{\circ}$ e $2^{\circ}$ graus, e dá outras providências. Brasília, DF: 1971. Disponível em:

$<$ http://www.planalto.gov.br/ccivil_03/leis/L5692.htm>. Acesso em: 10 jun. 2018.

BRASIL. Lei no 9.394, de 20 de dezembro de 1996. Estabelece as diretrizes e bases da educação nacional. Brasília, DF: 1996. Disponível em:

$<$ http://www.planalto.gov.br/ccivil_03/LEIS/L9394.htm>. Acesso em: 20 mai. 2018.

BRASIL. Lei $\mathbf{n}^{0}$ 11.161, de 5 de agosto de 2005. Dispõe sobre o ensino da língua espanhola. Brasília, DF: 2005. Disponível em: <http://www.planalto.gov.br/ccivil_03/_ato20042006/2005/lei/111161.htm>. Acesso em: 10 jun. 2018.

BRASIL. Lei $\mathbf{n}^{\mathbf{0}} \mathbf{1 3 . 4 1 5}$, de 16 de fevereiro de 2017. Altera as Leis $\mathrm{n}^{\mathbf{0}}$ 9.394, de 20 de dezembro de 1996, que estabelece as diretrizes e bases da educação nacional, e 11.494, de 20 de junho 2007, que regulamenta o Fundo de Manutenção e Desenvolvimento da Educação Básica e de Valorização dos Profisssionais da Educação, a Consolidação das Leis do Trabalho - CLT, aprovada pelo Decreto-Lei $n^{\circ} 5.452$, de $1^{\circ}$ de maio de 1943, e o Decreto-Lei $n^{\circ} 236$, de 28 de fevereiro de 1967; revoga a Lei ${ }^{\circ} 11.161$, de 5 de agosto de 2005; e institui a Política de Fomento à Implementação de Escolas de Ensino Médio em Tempo Integral. Brasília, DF: 2017b. Disponível em: < http://www.planalto.gov.br/ccivil_03/_Ato20152018/2017/Lei/L13415.htm\#art22>. Acesso em: 10 jun. 2018.

BRASIL. Parâmetros Curriculares Nacionais: Ensino Médio. Brasília: MEC/Secretaria de Educação Média e Tecnológica, 1999.

BRASIL. Parâmetros Curriculares Nacionais: terceiro e quarto ciclos do ensino do ensino fundamental: língua estrangeira. Brasília: MEC/SEF, 1998.

BRASIL. Orientações curriculares para o Ensino Médio (OCEM): Linguagens, Códigos e suas Tecnologias. Vol. 1. Brasília: MEC/SEB, 2006. 
BRASIL. Resolução no 58, de 22 de dezembro de 1976. Brasília, DF: 1976. Disponível em: $<$ http://www.helb.org.br/index.php/acervo-de-documentos/119-resolucao-no-58-de-22-dedezembro-de-1976>. Acesso em: 10 jun. 2018.

CAMPOS, C. M. A política da língua na era Vargas: proibição do falar alemão e resistências no Sul do Brasil. Campinas: Ed. Unicamp, 2006.

CARDOSO, T. M. R. F. L. As luzes da educação: fundamentos, raízes históricas e práticas das aulas régias no Rio de Janeiro (1759-1834). Bragança Paulista: EDUSF, 2002.

ESPÍRITO SANTO, Diogo Oliveira; SANTOS, Kelly Barros. A invenção do monolinguismo no Brasil: por uma orientação translíngue em aulas de "línguas". Calidoscópio, São Leopoldo, v. 16, n. 1, p. 152-162, 2018.

FOGAÇA, F. C.; GIMENEZ, T. N. O ensino de línguas estrangeiras e a sociedade. Revista Brasileira de Linguística Aplicada, Belo Horizonte, v. 7, n. 1, p. 161-182, 2007.

FRITZEN, M. P. "Ich kann mein Name mit letra junta und letra solta schreib": deutschportugiesisches Code-Switching in einer Grundschule im südbrasilianischen

Immigrationsgebiet. Pandaemonium Germanicum, São Paulo, v. 11, p. 125-156, 2007.

GUEDES, M. Q. Parâmetros Curriculares Nacionais ou o currículo oficial? Revista InterAção, Santa Maria, v. 27, n. 2, p. 85-99, 2002.

KERSCH, D. F.; SAUER, C. M. A sala de aula de alemão LE para falantes de dialeto: realidades e mitos. Linguagem \& Ensino, Pelotas, v. 13, n. 1, p. 183-203, 2010.

KUMARAVADIVELU, B. Beyond Methods: Macrostrategies for Language Teaching. New Haven \& London: Yale University Press, 2003.

KUMARAVADIVELU, B. The Postmethod Condition: (E)merging Strategies for Second/Foreign Language Teaching. TESOL Quarterly online, v. 28, n. 1, p. 27-48, 1994.

KUMARAVADIVELU, B. Toward a Postmethod Pedagogy. TESOL Quarterly online, v. 35, n. 4, p. 537-560, 2001.

KUMARAVADIVELU, B. Understanding language teaching: From method to postmethod. New York: Routledge, 2006.

LEFFA, V. J. O professor de línguas estrangeiras: do corpo mole ao corpo dócil. In: FREIRE, M. M.; ABRAHÃO, M. H. V.; BARCELOS, A. M. F. (Orgs.). Linguística Aplicada e contemporaneidade. São Paulo: ALAB/Pontes, 2005, p. 203-218.

MEIRELES, S. M. Língua estrangeira e autonomia: um exemplo a partir do ensino de alemão no contexto brasileiro. Educar, Curitiba, v. 20, p. 149-164, 2002.

NEUNER, G.; HUNFELD, H. Methoden des fremdsprachlichen Deutschunterrichts. Eine Einführung. Fernstudieneinheit 4. Berlin: Langenscheidt / Universität Gesamthochschule Kassel (GhK), 1993. 
PAIVA, J. M. Colonização e catequese. São Paulo: Cortez, 1982.

PAIVA, V. L M. O. A LDB e a legislação vigente sobre o ensino e a formação de professor de língua inglesa. In: STEVENS, C. M. T.; CUNHA, M. J. C. (Orgs.) Caminhos e colheitas: ensino e pesquisa na área de inglês no Brasil. Brasília: Editora UNB, 2003, p. 53-84.

PAULANI, L. M. A inserção da economia brasileira no cenário mundial: uma reflexão sobre a situação atual à luz da história. Boletim de Economia e Política Internacional, Ipea, v. 10, p. 89-102, 2012.

POCHMANN, M. Política social na periferia do capitalismo: a situação recente no Brasil. Ciência \& Saúde Coletiva, Rio de Janeiro, v. 12, n. 6, p. 1477-1489, 2007.

PRABHU, N. S. There ist no best method - why? TESOL Quarterly online, v. 24, p. 161$176,1990$.

RÖSLER, D. Deutsch als Fremdsprache: Eine Einführung. Stuttgart/Weimar: J.B. Metzler, 2012.

SAVIANI, D. História das Ideias Pedagógicas no Brasil. Campinas: Autores Associados, 2007.

SCHWARCZ, L. M. A longa viagem da biblioteca dos reis: do terremoto de Lisboa à Independência do Brasil. São Paulo: Companhia das Letras, 2002.

SILVA, F. M. Dos PCN LE às OCEM: o ensino de língua inglesa e as políticas linguísticas educativas brasileiras. Pesquisas em Discurso Pedagógico, Rio de Janeiro, v. 1, 2015, s/p.

Sindicato dos Profissionais em Educação no Ensino Municipal de São Paulo (SINPEEM). LDB - Comentário. Disponível em: <https://www.sinpeem.com.br/sites/arquivos/arquivos/ downloads/ldb2003.pdf.pdf>. Acesso em: 15 jun. 2018.

SOARES, M. Português na escola - História de uma disciplina curricular. In: BAGNO, M. (Org.). Linguística da norma. São Paulo: Edições Loyola, 2002.

UPHOFF, D. Uma pequena história do ensino de alemão no Brasil. In: BOHUNOVSKY, R. (Org.). Ensinar alemão no Brasil: contextos e conteúdos. Curitiba: Editora UFPR, 2011, p. 13-30.

YOUNG, M. From Constructivism to Realism in the Sociology of the Curriculum. Review of Research in Education, SAGE Journals, v. 32, p. 1-28, 2008. 